

\title{
Editorial
}

\section{The glut of graduate paramedics - what do we do with them?}

\author{
Malcolm Boyle $\mathrm{PhD}^{1}$, Jaime Wallis $\mathrm{BEH}\left(\right.$ Paramedic $^{1}$
}

\author{
Affiliation: \\ ${ }^{1}$ Monash University, Victoria
}

A recent letter from the Council of Ambulance Authorities (CAA) to Australian and New Zealand universities about the large number of student paramedics in Australian and New Zealand universities under training makes for an interesting read (1). Moreover, what power or influence does the CAA have to encourage a change in university paramedic student intakes?

Universities are unlikely to decrease their intake numbers as it directly correlates with a decrease in funds, which in some cases is used to offset decreased funds in other areas. Universities do not really have a social conscience when it comes to producing graduates, they may say they do, but do they really - just look at the numbers. And can you believe the employment numbers spruiked at university open day - more like lies, damned lies and statistics!

A paramedic student recently called the Neil Mitchell talk-back program on 3AW, a Melbourne radio station, complaining about being 'exploited' due to a lack of graduate paramedic positions within Victoria, Australia. The student criticised the number of students that universities were putting through paramedic courses when there is an obvious lack of graduate positions at the end of the course (2). Maybe students need to think about moving interstate or overseas to gain employment, many graduates from other professions have to do this. Students need to realise that getting into an ambulance service is now more difficult and challenging than it once was. Once a student successfully completes a graduate program and is qualified, a period of time working interstate makes one more employable. At this point, gaining employment back in the paramedic's home state should be easier. So is relocating to another state for one to two years such a drastic inconvenience in your overall working life?

The ambulance services are not going to complain about an excess of graduates to choose from, it allows them to theoretically pick 'the cream of the crop' thereby ensuring a group of graduates who, more than likely, will meet the requirements of the graduate program without additional work or resources.

A double degree, such as paramedic/nursing or paramedic/public health promotion, provides the graduate with a better chance of getting a job after completing their university course. Graduates who have only the single 'paramedic' degree may struggle to gain employment in the broader pre-hospital care sector, like the mining industry, as they have no prior experience. Pinning one's hope on gaining employment in their chosen ambulance service is flirting with disaster in a career sense, as has been highlighted by the student on the Neil Mitchell program.

A commentary by lan Peate in the Journal of Paramedic Practice in late 2014 raised the issue of the London Ambulance Service (LAS) recruiting qualified paramedics and graduate paramedics from international destinations, such as Australia, which may affect the number and quality of staff remaining (3). It now appears the practice of LAS employing Australian graduate paramedics is not an issue in Australian, in some cases it may be the only place graduates can get a job as a paramedic within a reasonable timeframe after they graduate. Recent graduates who have been employed by LAS are enjoying the experience, both work-wise and socially, with the ability to travel to destinations in Europe on days off.

It will be interesting to see what transpires in 2016 as a result of the CAA letter, but I doubt very little will change and universities will continue to take large numbers of students with limited jobs in sight. 
This issue starts with a commentary by Davidson and Forbes on the availability and utilisation of new technologies within the prehospital environment and how this may change clinical practice in the future (4). The article by O'Meara and colleagues reports on a collaborative project undertaken in rural Ontario, Canada, and how the community was engaged during the development and successful implementation of a community paramedicine program (5). The article by Ramothwala and colleagues investigated the ability of paramedic students to accurately measure a blood pressure in quiet and noisy environments (6). Rogers and colleagues delve into the view of paramedics in Western Australia about palliative care, what constitutes palliative care, and the education needed to deal with it as an operational paramedic (7). Emond and colleagues investigated final year paramedic student views and understanding of mental health plus the pre-hospital management and found many misconceptions that were changed following completion of a subject on mental health (8).

As this is the final issue for 2015 we would like to thank the readership for your ongoing support of the journal and wish the readership a merry Christmas and happy New Year and hope you will join us for the first issue of 2016 in February.

Dr Mal Boyle

Editor

Australasian Journal of Paramedicine

Jaime Wallis

Department of Community Emergency Health \& Paramedic Practice

Monash University

\section{References}

1. Council Ambulance Authorities. CAA Position Statement - Higher Education Paramedic Student Enrolment Numbers 10th June 2015.

2. Bourke J. Victorian paramedic student says she feels exploited following ambulance job 'freeze'. [Web Page]: 3AW; 2015. Available at: www.3aw.com.au/news/ambulance-victoria-accused-of-exploiting-paramedic-students-following-freeze-on-jobs20151007-gk35xl.html [Accessed 13 October 2015].

3. Peate I. Ethical Recruitment and Employment of Internationally Educated Paramedics. Journal of Paramedic Practice 2014;6(10):500-1.

4. Davidson K, Forbes M. Pre-hospital medicine: A glimpse of the future. Australasian Journal of Paramedicine 2015;12(5).

5. O'Meara P, Ruest M, Martin A. Integrating a Community Paramedicine program with local health, aged care and social services: An observational ethnographic study. Australasian Journal of Paramedicine 2015;12(5).

6. Ramothwala L, Stassen W, Stein W. The accuracy of manual blood pressures obtained by paramedic students in a quiet simulated and roadside environment. Australasian Journal of Paramedicine 2015;12(5).

7. Rogers I, Shearer F, Rogers J, Ross-Adjie G, Monterosso L, Finn J. Paramedics' perceptions and educational needs with respect to palliative care. Australasian Journal of Paramedicine 2015;12(5).

8. Emond K, Furness S, Deacon-Crouch M. Undergraduate paramedic students' perception of mental health using a pre- and postquestionnaire. Australasian Journal of Paramedicine 2015;12(5). 